\title{
Lilijana Žnidaršičc Golec
}

\section{NOVO O PRIMOŽU TRUBARJU IN TRŽAŠKEM ŠKOFU PETRU BONOMU V NOTARSKI LISTINI IZ SREDE JUNIJA 1541}

Čeprav je bilo tako Primožu Trubarju (ok. 1508-1586) kot Petru Bonomu (1458-1546) posvečene že razmeroma veliko raziskovalne pozornosti (Brazzano 2005; Cavazza 2007; Jerše 2009), ${ }^{1}$ je preučevalcem njunega življenja ostajala nepoznana notarska listina, izdana v Trstu 15. junija 1541. Da so raziskovalci listino spregledali - njen prepis hrani tržaški škofijski arhiv, ${ }^{2}$ utegnili pa bi jo najti tudi kje drugje -, je mogoče sklepati na podlagi dejstva, da o njej molčijo vidnejša biografska dela o Trubarju in Bonomu (Rupel 1962; Rajhman 1982; Brazzano 2005). Do zdaj širši javnosti znani podatki o vezeh med Trubarjem in Bonomom sicer niso maloštevilni, nekateri od njih se povrhu tega nanašajo prav na leto 1541. Kar zadeva Trubarjevo navzočnost na Bonomovem dvoru v Trstu, je ta prvič izpričana poldrugo desetletje prej, 7. marca 1526 (Golec 2008a, 26). Tega dne je mladi Trubar skupaj s petimi drugimi osebami iz kroga škofa Bonoma, večinoma tržaškimi duhovniki, nastopil kot priča pri zapisu oporoke škofovega bratranca Lenarta Bonoma, »doktorja obojega prava, tržaškega [stolnega] dekana in kanonika«. Zapis je nastal v hiši vicedomina (notarja) Janeza Krstnika Peterlina, pri čemer naj poudarim, da je bila druga priča s priimkom Peterlin, Peter Peterlin, v drugi

1 Omenjam le nekaj del iz obdobja zadnjih dveh desetletij. Prim. Rajšp 2018.

2 Archivio storico diocesano di Trieste, Carteggio Miscellaneo (1406-1802), busta 1.

3 Prim. objavo Rajhmanovega biografskega članka na spletni strani http://www.slovenska-biografija.si/oseba/sbi729148/\#slovenski-biografski-leksikon, dostop 16 . novembra 2019. 
polovici štiridesetih let 16. stoletja podobno kot Trubar tarča obtožb zaradi izražanja protestantskih stališč. Od Trubarja nekaj let starejši Peter, najverjetneje sin vicedomina Janeza Krstnika in pozneje tržaški stolni kanonik, se je moral v začetku leta 1548 zagovarjati zaradi vere kot edini klerik na sodnem procesu v Trstu (Cavazza 2006, 102; Žnidaršič Golec 2019a, 413-14). Oporoka škofovega bratranca Lenarta, ob kateri sta se 7. marca 1526 Trubar in Peter Peterlin morda videla prvič, pa je za nas zanimiva tudi z vsebinskega vidika. Razkriva namreč, da je imel umirajoči Lenart na ožjem Kranjskem župnijo Ig, kjer je vsaj občasno živel, kar nam lahko pomaga pri iskanju pravega odgovora na vprašanje, kako je Trubar sploh prišel v stik s škofom Bonomom (Golec 20o8b, 13-14). Toda vrnimo se k letnici 1541 in si najprej poglejmo že dolgo znane vire iz tega leta. Pred 135 leti, leta 1884, je bralcem Ljubljanskega zvona večino teh kratko predstavil Lovro Žvab, opirajoč se pri tem na zapise tržaških vicedominov in izpise tržaškega arhivarja, knjižničarja in zgodovinarja Luigija de Jennerja (1803-1868) (Žvab 1884).

V gradivu, ki ga je povzel Žvab, Trubarja srečamo štirikrat: prvič 29. aprila $1541 \mathrm{v}$ vlogi priče v véliki dvorani tržaške škofijske palače pri nakupu hiše »za Pasquo« (hčer Nikolaja iz Portogruara); drugič 1. junija 1541 kot »upravnika bratoma Ivanu in Jeronimu Brati«, fevdnikoma tržaškim škofom pripadajoče posesti v Kastelcu pri Socerbu - tej sta se zdaj odpovedala v korist skrbnika Bonomovih mladoletnih vnukov Antonia Della Spade; tretjič 13. junija $1541 \mathrm{v}$ vlogi priče pri formalni izročitvi kastelske posesti Della Spadi; četrtič 9. avgusta 1541, znova v vlogi priče pri izstavitvi listine, zadevajoče posest omenjene gospe Pasque (Žvab 1884). Da se je Trubar v Trstu zadrževal že pred 29. aprilom 1541, po drugi strani izvemo iz pisma zdravnika Melhiorja Cerronija avguštinskemu patru Giuliu Della Roveri z dne 7. aprila 1541. V pismu verskemu somišljeniku Della Roveri, ki mu je bila tedaj že tesno za petami beneška inkvizicija, Cerroni omenja kontakt $\mathrm{z}$ »duhovnikom Primožem» (Brazzano 2005, 323). Kot zaupnika škofa Bonoma (familiar) je Trubarja na enem od zaslišanj inkvizicijskega sodišča v Benetkah zgodaj poleti 1541 označil tudi sam Della Rovere, vendar naj ga ne bi poznal osebno (Cavazza 2006, 95, 97). Če ta trditev drži, potem si moramo pač na novo postavi- 
ti vprašanje, ali se je Trubarjevo drugo nedvoumno dokumentirano bivanje v Trstu v resnici začelo med adventom 1540 (ali kaj prej). Težko si namreč predstavljamo, da bi se Della Rovere, ki je tega leta na povabilo škofa Bonoma v Trstu prevzel adventno pridiganje v italijanščini, ne srečal s Trubarjem, Bonomovim zaupnikom in za »evangeljsko stvar« vnetim pridigarjem slovenskega jezika. Bolj kot s časovnega vidika je nov premislek sicer potreben $\mathrm{z}$ vidika okoliščin, ki so Trubarja privedle k temu, da je zapustil Ljubljano (in službo ljubljanskega stolnega pridigarja) ter se podal k škofu Bonomu v Trst.

Nobenega dvoma vsekakor ni, da je Bonomo Trubarju zaupal razne naloge spomladi in poleti 1541. Kot smo videli zgoraj, se v virih "prve roke« Trubarjevo ime pojavlja od 7. aprila do 9. avgusta, pri čemer je vir, o katerem bo v nadaljevanju tekla beseda, nastal sredi junija 1541. Gre, kot rečeno, za prepis notarskega instrumenta, ki sem ga 16. maja 2014 našla med evidentiranjem arhivskega gradiva v Škofijskem zgodovinskem arhivu v Trstu (Žnidaršič Golec in Volčjak 2015, 7). Sistematično iskanje, izpisovanje in objavljanje podatkov iz gradiva, "pomembnega za Slovenijo in Slovence v tujih arhivih«, poteka že vrsto let, najdba pa potrjuje, da si projekt evidentiranja, ki ga izvajajo Arhiv Republike Slovenije in drugi slovenski arhivi, zasluži širšo pozornost in podporo. ${ }^{4}$ Notarski zapis, na katerega sem naletela v navedenem arhivu, je del prvega fascikla fonda oziroma zbirke »Carteggio Miscellaneo (Razna korespondenca). Zapis v latinskem jeziku naznanja, da je v sredo, 15. junija 1541, Peter Bonomo, po božji milosti tržaški škof in grof, v stolni cerkvi sv. Justa Trubarja imenoval za svojega pravega in zakonitega zastopni$\mathrm{ka}$, odposlanca in posebnega pooblaščenca. Za »suum verum, certum, legitimum, et indubitatum, procuratorem, nuncium, et commissum specialem« Bonomo svojega kaplana Primoža Trubarja slovesno postavlja zato, da bi Trubar pred kraljevim veličanstvom - Ferdinandom I. (kralj 1526-1556, cesar 1556-1564) - in kraljevimi svétniki na Dunaju škofa zastopal v sporu z Martinom Kusmanom (Cusman). Kusman, kastelan gradu Socerb, in (drugi) socerbski oskrbniki naj bi se namreč polastili škofovih desetin, dohodkov in pravic. Trubar naj bi pri kralju in nje-

$4 \mathrm{O}$ (pred)zgodovini tega dolgoročnega projekta Šmid 2009. 
govih svétnikih dosegel dvoje: dokazal naj bi, da ti dohodki in pravice pripadajo tržaškim škofom, kot nične pa izpodbil dokaze, ki bi jih predstavila Kusmanova stran. Čeprav bi to zahtevalo širša pooblastila, bi Trubar kralja ali njegov svèt lahko zaprosil za potrdila o pravicah in svoboščinah, ki so jih pridobili in se ravnali po njih Bonomovi predhodniki ali Bonomo sam. Škof Trubarju nazadnje podeli še pravico do imenovanja in odpoklica enega ali več nadomestnih zastopnikov $\mathrm{z}$ enakimi ali omejenimi pristojnostmi, kot jih z listino prejema Trubar. Pri overovitvi zapisa navzoči priči sta bila kanonik tržaškega stolnega kapitlja Jakob de Mirissa in kaplan ter zakristan tržaške stolne cerkve Frančišek de Rubeis.

Vsebina tega v več pogledih zgovornega dokumenta sproža vsaj dve pomembni vprašanji, nanašajoči se na ozadje Bonomove izbire Trubarja in na uspešnost Trubarjevega angažmaja na Dunaju. Odgovor na vprašanje, zakaj je Bonomo za reševanje nelahke posestnopravne zadeve pooblastil ravno Trubarja, se zdi na dlani. Še zlasti če pomislimo, da je Bonomo Trubarju nalagal različne opravke že v Trubarjevih mladih letih ter ga - očitno zelo zadovoljen s svojim mladim »služabnikom« in (nekdanjim) pevcem - gmotno in drugače podpiral na nadaljnji življenjski poti. Kot bodoči duhovnik Trubar ni bil deležen le pouka na Bonomovem tržaškem dvoru, temveč mu je škof gmotno omogočil ali olajšal tudi študij na univerzi na Dunaju, po mašniškem posvečenju pa mu je zagotovil mesti vikarja v Loki pri Zidanem Mostu in župnika oziroma župnijskega vikarja v ugledni župniji Laško. Na obeh dušnopastirskih postojankah se je Trubar izkazal kot spreten, zaupanja vreden gospodar (Žnidaršič Golec 2019b, 387). Po drugi strani je na Bonomovo odločitev za Trubarja zagotovo vplivalo dejstvo, da posestna razmerja na območju Socerba in bližnjega Kastelca, kjer so imeli svoje podložnike tudi tržaški škofje, Trubarju niso bila neznana; navsezadnje je v zvezi s kastelsko posestjo malo prej zastopal brata iz koprske patricijske družine Brati (Žvab 1884, 43-44). Precej bolj hipotetičen je za zdaj naš odgovor na vprašanje, ali je Trubar škofova pričakovanja izpolnil. Domnevi, da se je dobro lotil naloge in jo srečno pripeljal h koncu, lahko opremo na dva podatka, tj. da je Trubar tisti čas od Bonoma do- 


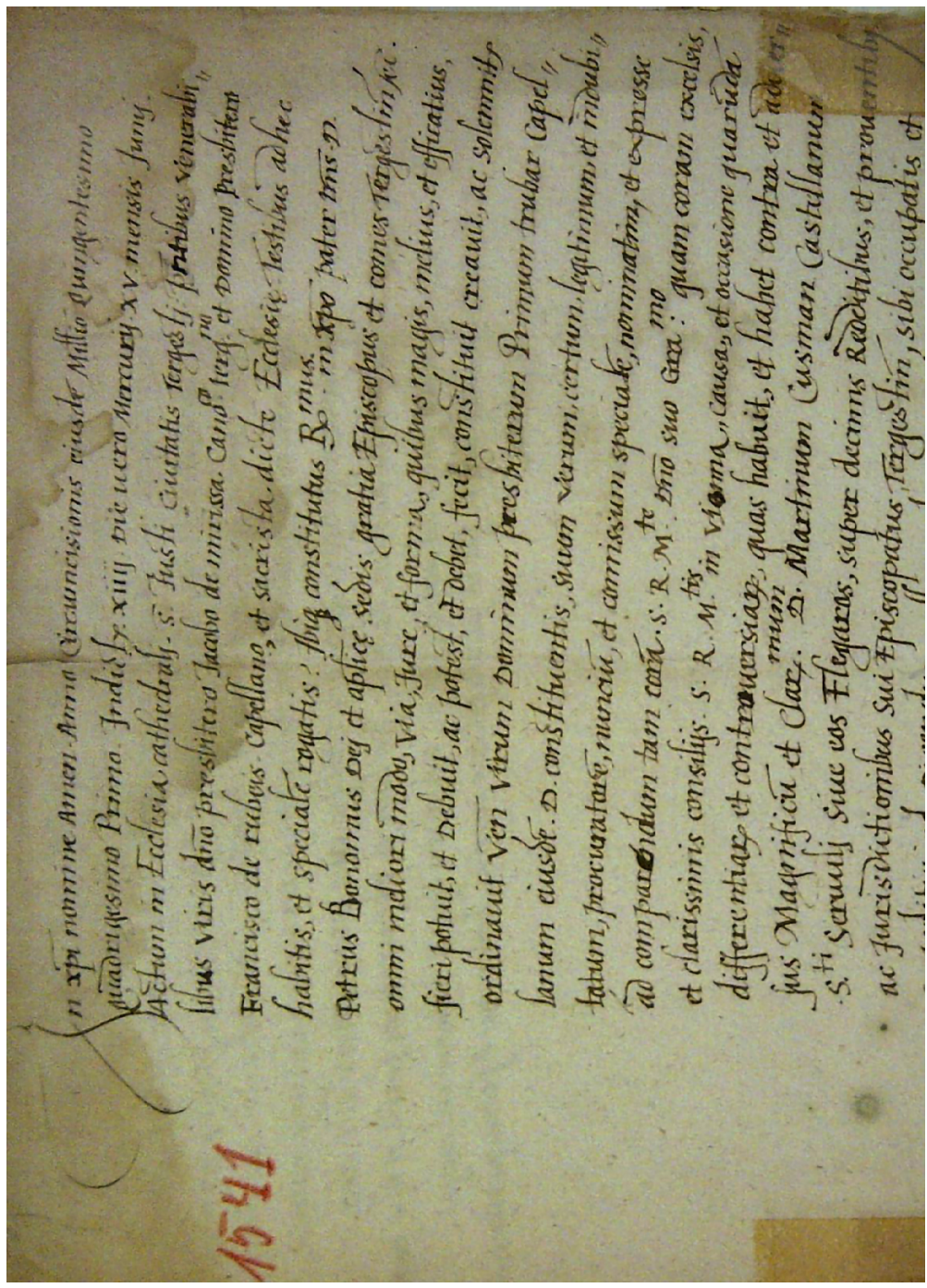

Prva stran prepisa notarske listine $\mathrm{z}$ dne 15 . junija 1541, izsek (Archivio storico diocesano di Trieste, Carteggio Miscellaneo, busta 1). Tržaški škof Peter Bonomo imenuje Primoža Trubarja za zastopnika v sporu s socerbskim kastelanom Martinom Kusmanom. 
bil razmeroma donosen beneficij sv. Maksimilijana v Celju in da je z Bonomovo pomočjo pred jesenjo 1543 zasedel še kanonikat stolnega kapitlja v Ljubljani (Žnidaršič Golec 2019b, 387-88). Da bi domnevi postavili na trdnejše temelje, bi bilo seveda treba izpeljati širše zastavljeno raziskavo. Ta bi morala poleg tržaških arhivov vključevati tudi arhivsko gradivo na Dunaju, kjer je imel sedež »Reichshofrat«, cesarski (državni) dvorni svet, kot zadnja pritožbena instanca v tako imenovanih komornih zadevah (Žnidaršič Golec 2019b, 387).

Notarska listina iz srede junija 1541, katere prepis ni povsem popoln - manjka notarjevo (vicedominovo) ime -, o Trubarju in Bonomu ne prinaša česa revolucionarno novega, kljub temu pa sta njeno odkritje in objava dragoceni. ${ }^{5}$ In to ne samo zato, ker ima velik zgodovinopisni pomen pravzaprav vse, kar je bilo o Trubarju in Bonomu zapisanega še $v$ času njunega življenja. Čeprav gre za drobec v vrsti drugih virov, kontekstualni pretres listine dodatno osvetljuje odnos med Bonomom in pol stoletja mlajšim Trubarjem. Poleg novih podatkov in, posledično, novih poudarkov pa so dragocena tudi vprašanja, na katera bodo odgovarjale, kot je upati, prihodnje raziskave.

\section{VIRI IN LITERATURA}

\section{VIR}

Prepis notarske listine $\mathrm{z}$ dne 15. junija 1541. V Archivio storico diocesano di Trieste, Carteggio Miscellaneo (1406-1802), busta 1.

\section{LITERATURA}

Brazzano, Stefano. 2005. Pietro Bonomo (1458-1546), diplomatico, umanista e vescovo di Trieste: La vita e l'opera letteraria. Trieste: Parnaso.

5 Objavo transkripcije tega vira pa tudi njegovo podrobnejšo obravnavo najdemo v Žnidaršič Golec 2019b, 386-87, 391. Vsebina listine je sicer doživela ustno predstavitev že na predavanju, ki ga je 8. junija 2015 organiziralo Društvo slovenskih izobražencev v Trstu. Prim. Trubar 2015, obj. na spletni strani https://www.noviglas. eu/trubar-in-njegov-trst/, dostop 17. novembra 2019. 
Cavazza, Silvano. 2006. »Bonomo, Vergerio, Trubar. Propaganda protestante per terre di frontiera.« V »La gloria del Signore«: la riforma protestante nell'Italia nord-orientale, ur. Gianfranco Hofer, 90-157. Mariano del Friuli (GO): Edizioni della Laguna.

---. 2007. »Bonomo, Vergerij, Trubar.« Stati inu obstati: revija za vprašanja protestantizma 7 (5-6): 62-81.

Golec, Boris. 2008a. »Najzgodnejša pričevanja o Primožu Trubarju: Omembe, podpisi in pečati med letoma 1526 in 1545 " Časopis za zgodovino in narodopisje $79=\mathrm{n}$. v. $44(3-4): 24-41$.

---. 2008b. »Trubarjeve prve šole.« Šolska kronika 17 (41) (1): 7-27.

Jerše, Sašo, ur. 2009. Vera in hotenja. Študije o Primožu Trubarju in njegovem času. Ljubljana: Slovenska matica.

Rajhman, Jože. 1982. »Trubar, Primož (med 1507 in 1509-1586).«V Slovenski biografski leksikon 13 (Trubar - Vodaine), ur. Alfonz Gspan, Jože Munda in Fran Petrè. Ljubljana: Slovenska akademija znanosti in umetnosti.

Rajšp, Vincenc. 2018. „Die Wahrnehmung des Reformators Primus Truber zu Lebzeiten und danach." Württembergisch Franken Jahrbuch 102, 19-44. Schwäbisch Hall: Historischer Verein für Württembergisch Franken.

Šmid, Gašper. 2009. »Evidentiranje arhivskega gradiva v tujini.« Arhivi 32 (1): 85-93.

Trubar 2015. »Trubar in njegov Trst.« Novi glas, 23. junij 2015, https://www.noviglas. eu/trubar-in-njegov-trst.

Žnidaršič Golec, Lilijana. 2019a. »Konfesionalna mobilnost na Slovenskem v zgodnjem novem veku: Katoličani, luterani, kalvinci, judje." V Družbena in identitetna mobilnost $v$ slovenskem prostoru med poznim srednjim vekom in 2o. stoletjem, ur. Boris Golec, 407-45. Ljubljana: Založba ZRC, ZRC SAZU.

---. 2019b. »Primož Trubar - servitor in commissus specialis tržaškega škofa Petra Bonoma: Prispevek k Trubarjevi biografiji.«Kronika 67 (3), 383-94.

Žnidaršič Golec, Lilijana, in Jure Volčjak. 2015. "Trst, Italija.« V Evidentiranje arhivskega gradiva $v$ tujini. V letu 2014 zbrana dokumentacija o arhivskem gradivu $v$ tujini, ki se nanaša na Slovenijo in Slovence 11 (1), ur. Gašper Šmid, 7. Ljubljana: Arhiv Republike Slovenije.

Žvab, Lovro. 1884. »Črtica o Primoži Trubarji.«Ljubljanski zvon 4 (1): 41-45. 